\title{
A Systematic Approach of Resonant Tank Design for LLC Converters Implemented in Solar Photovoltaic Energy Storage Systems
}

\author{
Wayne Water \\ Boyuan Zhu \\ Queensland Micro- and Nano-technology Centre \\ Griffith University \\ Nathan, Australia \\ w.water@griffith.edu.au \\ boyuan.zhu@griffith.edu.au
}

\author{
Junwei Lu \\ Dale Butler \\ School of Engineering \\ Griffith University \\ Nathan, Australia \\ j.lu@griffith.edu.au \\ dalebutler.elec@gmail.com
}

\begin{abstract}
This paper discusses the design considerations of High Frequency (HF) magnetics to be used in Linear Level Control (LLC) converters. Most of LLC converter design starts with LLC parameters calculation. The magnetics are then designed to match the requirements. However, this is not always the most optimized result as the implemented magnetics does not operate at maximum efficiency. Therefore, this paper proposes systematic LLC converter design procedures to deal with this problem. A systematic approach of the magnetics design was conducted, and the introduced methodology is particularly suitable for LLC converters used in solar photovoltaic (PV) energy storage systems. A $350 \mathrm{~W}$ LLC converter example was examined and demonstrated. The efficiency performance is very consistent across the operating frequencies, in which the efficiency variation is less than $1.5 \%$.
\end{abstract}

Index Terms-- LLC resonant converter, PV energy storage system, high frequency magnetics.

\section{INTRODUCTION}

The number of PV installations has increased rapidly in recent years. For example, the U.S. will need to deploy a 70 times installed PV capacity (total installations in 2013) from now to 2050 [1]; in Australia, 93.55\% of PV installation was completed from 2010 to 2014, according to government data. However, the rapid increase of solar PV installations also imposes many problems in low voltage networks such as reverse power-flow and voltage-rise [2]. For this reason, a distributed energy storage concept becomes popular and effective for the mitigation of impacts caused by grid-tied solar PVs [2], [3].

In the traditional two-stage PV energy storage configuration, solar panels are connected in a series in regards to the required voltage level. This solar array is then connected with the battery bank through a current-source converter [4]. This configuration is very compact and easy to implement, but it imposes drawbacks of lower efficiency and low reliability.
For this reason, the advanced one-stage PV energy storage configuration introduced in this paper is attracting market interest. Each solar panel is equipped with an individual DCDC converter, in which the converter regulates the voltage level to the required battery charging range of 336 to $470 \mathrm{~V}$. The DC-DC converter also has a Maximum Power Point Tracking (MPPT) function in-built to obtain the maximum possible power of PV panels. Every solar panel unit is operating independently so that failure in one or more units does not affect operation of the whole system.

The benefits of one-stage PV energy storage structure are obvious. However, it also makes the performance of each DCDC convertor another key factor that affecting overall system efficiency. This paper discusses a systematic design procedure of LLC convertor which is particular adapted to the solar PV energy storage system comparing to the traditional design methodology.

\section{DESIGN CONCERNS OF PV ENERGY STORAGE SYSTEM}

A. System Requirements

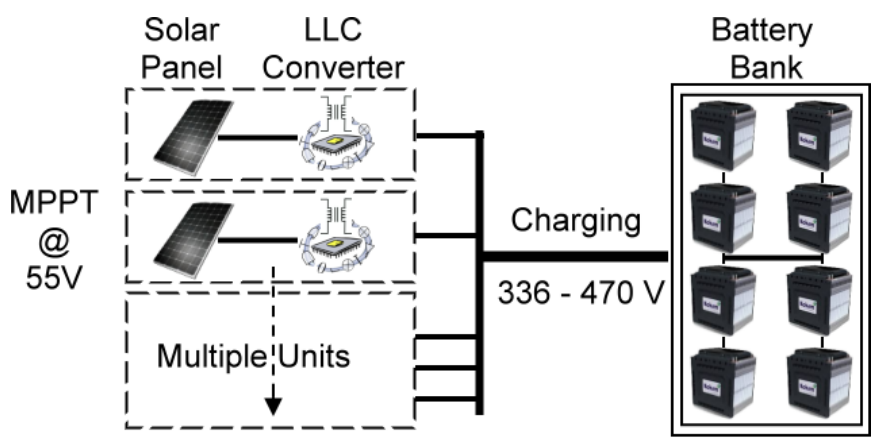

Fig. 1. Illustration of PV energy storage system configuration

The schematic of the one-stage solar PV energy storage system is shown in Fig. 1. In order to realize the one-stage PV 
energy storage configuration and benefits from its structure, some requirements must be met by the utilized converter: (1) compact and inexpensive; (2) galvanic isolation; (3) high efficiency; (4) high voltage gain ratio; (5) broad voltage regulation range; and (6) light load operation. Therefore, LLC resonant type converters with the utilization of HF isolation transformers have been selected as satisfactory.

\section{B. Design Challenges of LLC Converter}

LLC resonant converters have attracted great interest in past decades. The most fascinating part of the LLC resonant topology is its highly efficient performance due to the softswitching of Zero Voltage Switching (ZVS) or Zero Current Switching (ZCS), in which a resonant tank is required in the front end of the converter [5]. However, it is only in recent years that such converters have been more widely introduced onto the market due to the complexity of circuit behavior and difficulties of the resonant tank and its magnetic design [6] [9]. In particular, the redundant and repeated calculation process is another challenging task for engineers to tackle because it requires experience and time-consuming verification.

\section{DESIGN METHODOLOGY}

\section{A. Systematic Design Process}

The proposed design procedures are shown in Fig. 2. The first and most important step is to find out the most sufficient resonant frequency $f_{r}$. The $f_{r}$ is selected based on components availability, converter size, overall efficiency, and applications etc. Once the $f_{r}$ is confirmed, the magnetic material can be chosen and optimized for the best $f_{r}$ point. Due to the nonlinear behavior of the magnetic material, and the voltage variation requirement of LLC converters across the operating frequency ranges, a trade-off between efficiency and frequency can be found. An example of optimized $f_{r}$ selection will be presented in the following section.



Fig. 2. Design flowchart of LLC magnetics

\section{B. Design of Resonant Tank}

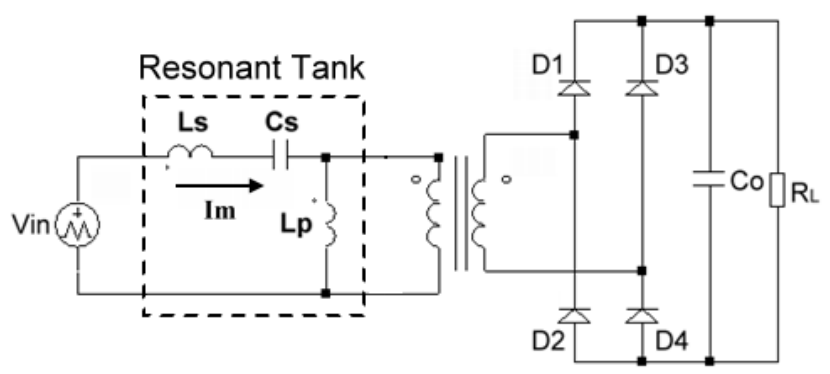

Fig. 3. LLC Resonant circuit schematic

A simplified converter schematic is shown in Fig. 3. The resonant tank is composed of the resonant inductor $\mathrm{L}_{\mathrm{s}}$, the magnetizing inductor $L_{p}$ and the resonant capacitor $C_{s}$. Selection of sufficient LLC parameters upon the requirements, while maintaining high efficiency, is another challenge. Since the design process is very tedious and repetitive, it is suggested to start the resonant tank design from selecting the $\mathrm{L}_{\mathrm{p}}$. The reason is because the $\mathrm{L}_{\mathrm{p}}$ is the most essential prerequisite in achieving ZVS condition. In order to switch on softly, it needs to ensure that enough current is flowing in the resonant tank when one switch (half bridge as the example) turns off before its complementary switch turns on. The noload current $\mathrm{I}_{\mathrm{m}}$ must be able to charge and discharge the drain to source capacitance $\mathrm{C}_{\mathrm{ds}}$ of the turning MOSFET, which can be represented as:

$$
I_{m}=C_{d s} S \frac{V_{\text {in }}}{t_{\text {dead }}}
$$

where $S$ is the number of MOSFETs in the switching circuitry, $V_{\text {in }}$ is the voltage across the resonant tank and $t_{\text {dead }}$ is the dead time between the upper and bottom MOSFETs. At resonance, the $L_{s}$ and the $C_{s}$ are in a series with zero impedance, in which the $I_{m}$ is a sinusoidal wave. Thus, the upper limit of the $L_{p}$ is now obtained:

$$
L_{p}=\frac{V_{\text {in }}}{4 f_{r} I_{m}}=\frac{t_{\text {dead }}}{4 f_{r} C_{d s} S}
$$

Care must be taken when applying ( 1 ) and ( 2 ) in the design process. Due to the inherent characteristics of the MOSFET and driver circuitry, the fall time, the turn-off delay time, and the driving signal propagation time need to be taken into account when obtaining the actual $t_{\text {dead }}$ in practice. The $t_{\text {dead }}$ assigned to the controlling signal usually has a slight difference when comparing to the actual signal exists in the circuitry. Once the $L_{p}$ is obtained, other parameters can be calculated in consequence accordingly. The voltage gain $G$ can be obtained from DC analysis [8], [9]:

$$
\frac{V_{s}^{\prime}}{V_{\text {in }}}=\frac{j \cdot \omega_{n} \cdot k}{j \cdot \omega_{n} \cdot\left(1+k-\frac{1}{\omega_{n}{ }^{2}}\right)+k \cdot\left(1-\omega_{n}{ }^{2}\right) \cdot Q}
$$

where $\omega_{n}$ is the ratio of the resonant frequency and switching frequency, $\mathrm{k}=L_{p} / L_{s}, \mathrm{Q}$ is the quality factor and $R_{E Q}=$ 
$8 / \pi^{2} \cdot R_{o} \cdot N^{2}$. ( $R_{o}$ is the load resistance). For ease of calculation, ( 3 ) is re-written with the elimination of the frequency factor, and derived as in ( 4 ) to find the maximum quality factor $Q_{\max }$ required for the system:

$$
Q_{\max }=\frac{1}{k \cdot G_{\max }} \sqrt{k+\frac{G_{\max }^{2}}{G_{\max }^{2}-1}}
$$

Thus, the rest of the resonant tank parameters are obtained with a pre-selected $f_{r}$ and inductance ratio $k$ (normally 5 8):

$$
\begin{gathered}
L_{s}=\frac{L_{p}}{k} \\
C_{s}=\frac{L_{s}}{Q_{\max }^{2} \cdot R_{E Q}{ }^{2}}
\end{gathered}
$$

Consequently, the switching frequency $f_{s}$ can be obtained:

$$
f_{s}=\frac{f_{r}}{\sqrt{1+k \cdot\left(1-\frac{1}{G^{2}}\right)}}
$$

\section{CASE STUdY OF A $350 \mathrm{~W}$ LLC CONVERTER}

To demonstrate the design concept, an example design of a $350 \mathrm{~W}$ LLC converter is presented. Magnetic material of MnZn TP4A is selected for the prototype transformer along with a core size of EE38/16/25 (L/W/H respectively in $\mathrm{mm}$ ). With a fixed input voltage of $55 \mathrm{~V}$ and $80 \%$ of maximum flux density $B_{\max }$ are specified for the design, the minimum requirement of winding turns is four turns at frequencies above $100 \mathrm{kHz}$. Power losses can be calculated according to the manufacturer's datasheet, and thus a core losses curve is depicted as shown in Fig. 4. It can be easily observed that the optimized frequency range for the core material is between $200 \mathrm{kHz}$ and $300 \mathrm{kHz}$; also, the core losses is less than two watts with winding turns greater than five turns. However, more winding turns results in a lower core loss but also results in a higher transformer copper loss. Thus, less winding turns should be selected while having the minimized and acceptable core losses. For this reason, winding turns of four, the $f_{r}$ of $300 \mathrm{kHz}$ and switching frequency ranges of $150 \mathrm{kHz}$ to $400 \mathrm{kHz}$ are chosen. Once transformer primary winding turns, the $f_{r}$ and the $f_{s}$ are selected, the rest of the parameters can be obtained based on calculations shown in the previous section.

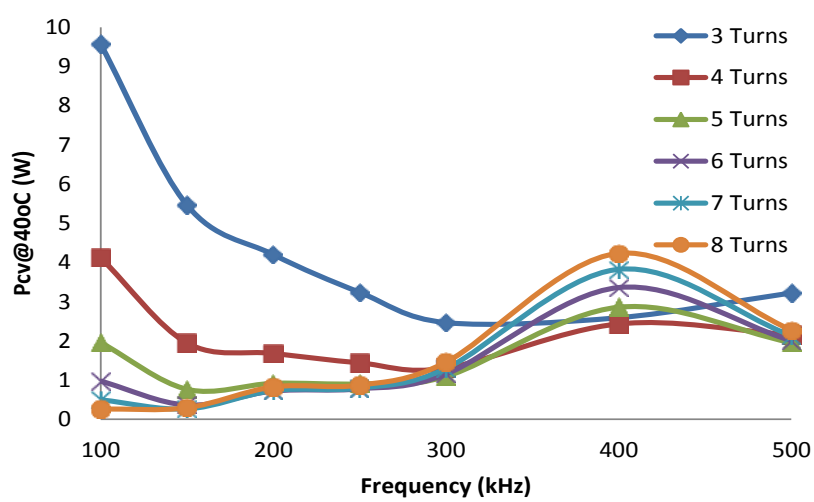

Fig. 4. Example of core losses at $55 \mathrm{~V}, 40^{\circ} \mathrm{C}$ with core EE38/16/25

The specifications of the exampled $350 \mathrm{~W}$ LLC converter in full bridge switching topology is tabulated as shown in Table I. The Infineon OptiMOS IPP110N20N3 MOSFET is used, in which it has the maximum output capacitance of 533 $p \mathrm{~F}$. A dead time of $151 n \mathrm{~S}$ is assigned in the driving signal, and the actual dead time applied to ( 2 ) by taking into account the driver performance (maximum 3A/2A source/sink current) is obtained as $151 \mathrm{nS}$. The prototype transformer was built with an inter-leaving winding structure to minimize the winding losses at this high frequency range (the current on the primary side is about 8 9 A at this power rating).

TABLE I

THE 350 W LLC TRANSFORMER AND CONVERTER SPECIFICATIONS

\begin{tabular}{|c|l|l|}
\hline Symbol & \multicolumn{1}{|c|}{ Parameters } & \multicolumn{1}{c|}{ Requirements } \\
\hline$P_{\text {out }}$ & Power rating & $350 \mathrm{~W}$ \\
\hline$V_{\text {in }}$ & Input voltage & $55 \mathrm{~V}(\mathrm{DC})$ \\
\hline$V_{s}^{\prime}$ & Output voltage & $336-470 \mathrm{~V}(\mathrm{DC})$ \\
\hline$V_{\text {nomial }}$ & Nominal voltage & $343 \mathrm{~V}(\mathrm{DC})$ \\
\hline$f_{r}$ & Resonant frequency & $300 \mathrm{kHz}$ \\
\hline$f_{s}$ & Switching frequency & $150 \sim 400 \mathrm{kHz}$ \\
\hline $\mathrm{N}$ & Transformer turn ratio & $4: 25$ \\
\hline $\mathrm{Q}$ & Quality factor & 0.21138 \\
\hline $\mathrm{G}$ & Gain & $0.98 \sim 1.37$ \\
\hline$L_{s}$ & Resonant inductor & $0.6 \mu \mathrm{H}$ \\
\hline$L_{p}$ & Magnetizing inductor & $8.3 \mu \mathrm{H}$ \\
\hline$C_{s}$ & Resonant capacitor & $470 \mathrm{nF}$ \\
\hline$C_{d s}$ & MOSFET capacitance & $533 \mathrm{pF}$ \\
\hline$t_{d e a d}$ & Dead time & $23 \mathrm{nS}$ \\
\hline
\end{tabular}

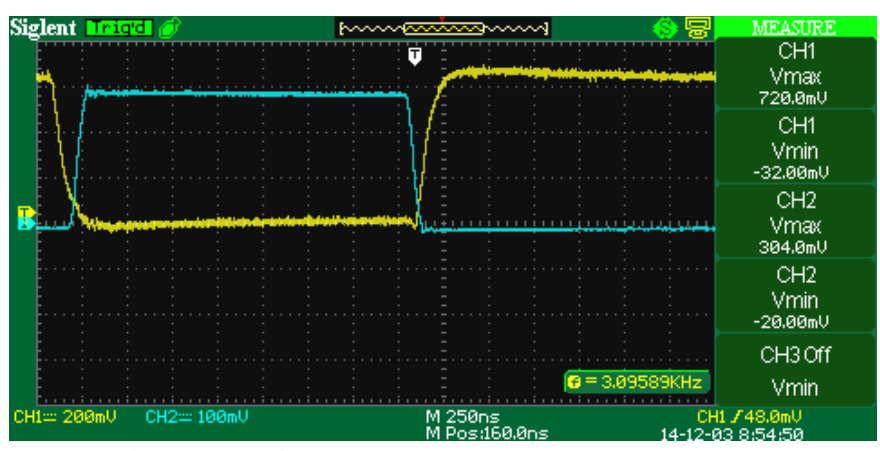

Fig. 5. Switching waveform at $300 \mathrm{kHz}$. Top MOSFET $\mathrm{V}_{\mathrm{gs}}(\mathrm{Ch} 1), \mathrm{V}_{\mathrm{ds}}(\mathrm{Ch} 2)$ 
Furthermore, a verification test was conducted to examine if the ZVS condition is achieved by measuring the gate to source signal $\mathrm{V}_{\mathrm{gs}}$ and drain to source voltage $\mathrm{V}_{\mathrm{ds}}$ of MOSFET in one switch arm. The waveform measurement shown in Fig. 5. The $\mathrm{V}_{\mathrm{ds}}$ falls down to zero when the $\mathrm{V}_{\mathrm{gs}}$ signal is assigned. This demonstrates that the ZVS condition is achieved as there is no cross-over between these two voltage signals.

The overall system efficiency curve of the prototype LLC converter is shown in Fig. 6. The testing setup is relatively simple by measuring the DC power input and output. The efficiency measurement was conducted at a constant $350 \mathrm{~W}$ load across the operational frequencies. Some comments are made according to the efficiency testing result. Firstly, the resonant frequency is shifted from the designed $300 \mathrm{kHz}$ to $270 \mathrm{kHz}$ due to the existing parasitic inductance. The LLC topology always achieves the best efficiency point at resonance due to the fulfillment of ZVS and ZCS condition. Secondly, the converter efficiency decreases dramatically when the frequency is above $300 \mathrm{kHz}$. This is are mainly attributed by the higher switching off loss and winding losses of the transformer. In order to improve the switching off loss, a smaller $\mathrm{L}_{\mathrm{p}}$ or a greater $L_{s}$ can be implemented. However, this also result in the reduction of the system's overall efficiency at lower frequencies. Furthermore, the efficiency variation is less than $1.5 \%$ by looking at the whole efficiency curve. The result represents that the converter performance is well suited to the use of solar PV energy storage applications.

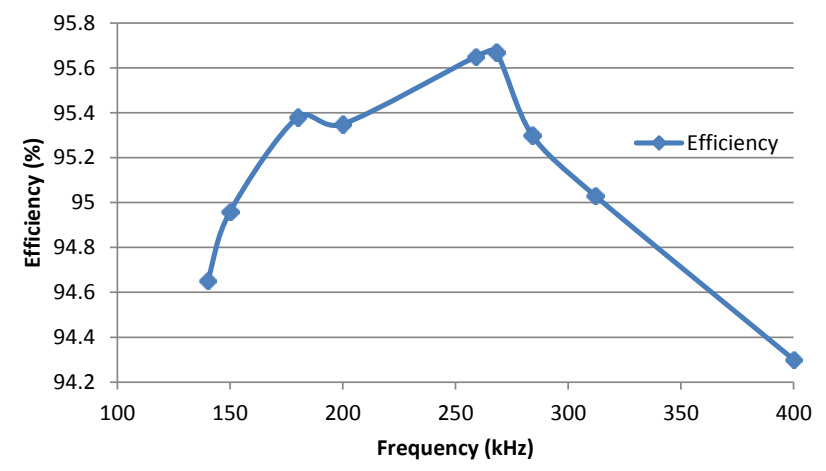

Fig. 6. $350 \mathrm{~W}$ LLC converter efficiency under full load condition

\section{REFERENCES}

[1] J. Morris, K. J. Calhoun and D. Seif, "Reducing Solar PV Soft Costs: A Focus on Installation Labor," in PVSC. $40^{\text {th }}$ Annu. IEEE Photovoltaic Specialist Conf., June. 2014, pp. 3356-3361.

[2] M. J. E. Alam, K. M. Muttaqi and D. Sutanto, "Mitigation of Rooftop Solar PV Impacts and Evening Peak Support by Managing Available Capacity of Distributed Energy Storage Systems, "IEEE Trans. on Power Systems, vol. 28, No. 4, pp. 3874-3884, Nov. 2013.

[3] C. A. Hill, M. C. Such, C. Dongmei, J. Gonzalez and W. M. Grady, "Battery Energy Storage for Enabling Integration of Distributed Solar Power Generation," IEEE Trans. on Smart Grid, vol. 3, No. 2, pp. 850857, June. 2012.

[4] Z. Wang, Z. Zou and Y. Zheng, "Design and Control of a Photovoltaic Energy and SMES Hybrid System with Current-Source Grid Inverter," IEEE Trans. on Applied Superconductivity, vol. 23, No. 3, pp. 5701505, June. 2013.
[5] B. Lu, W. Liu, Y. Liang, F. C. Lee and J. D. Wyk, "Optimal Design Methodology for LLC Resonant Converter," in APEC. 21st Annu. Applied Power Electron. Conf., pp. 19-23, Mar. 2006.

[6] D. Cheng, X. Dehong, Y. Zhang, C. Yi, Y. Okuma and K. Mino, "Impact of Dielectric Material on Passive Integration in LLC Resonant Converter," in PESC 2008. IEEE Power Electronics Specialists Conference, pp. 269-272, June. 2008

[7] W. Water and J. Lu, "Improved High-Frequency Planar Transformer for Line Level Control (LLC) Resonant Converters," Magnetic Letters, IEEE, vol. 4, pp. 1-4, Nov. 2013.

[8] W. C. Ju, "LLC DC/DC Resonant Converter with PLL Control Scheme," M.S. thesis, Electr. Eng., National Cheng Kung. Univ., Tainan, Taiwan, 2006.

[9] Sihun. Yang, S. Abe and M. Shoyama, "Design Consideration of Flat Transformer in LLC Resonant Converter for Low Core Loss," Power Electron. Conf., 2010, vol. 1, pp. 343-348. 